\title{
Comparison of alexithymia in schizophrenia and somatic diseases
}

\author{
Nadir A. Aliyev ${ }^{*}$, Teymur A. Gafarov ${ }^{1}$, Zafar N. Aliyev ${ }^{2}$ and Eldar R. Haqverdi ${ }^{1}$ \\ ${ }^{1}$ Azerbaijan State Advanced Training Institute for Doctors named by A. Aliyev department of psychiatry and drug addiction, Baku, Azerbaijan Republic \\ ${ }^{2}$ Azerbaijan Medical State University, Department of Psychiatry Baku City, Azerbaijan Republic
}

\begin{abstract}
Somatic diseases, schizophrenia paranoid form the basis of the results of our study examined and established high level alexithymia in both groups. Paranoid schizophrenia patients with higher marks alexithymia level than these somatic diseases. The negative symptoms of schizophrenia patients in weight, compared to about two times more positive signs included. The negative symptoms of schizophrenia, that is a positive correlation with the level of alexithymia. Paranoid schizophrenia, its sense of social isolation is difficult to describe their lack of ability to understand the higher level of relations between individuals, conflicts and patients and when alexithymia and other. The results of these studies show that in future relations and the prospects for the study of schizophrenia and have great relevance in alexithymia.
\end{abstract}

\section{Introduction}

The alexithymia (the word comes from Greek a (a, "no", the negating alpha privative), $\lambda \dot{\varepsilon} \xi ı \varsigma$ (léxis, "word”), and $\theta u \mu o ́ c$ (thymos, "emotions", but understood as having the meaning "mood"), literally meaning "no words for mood"), as a psychological characteristic of personality, it has the following features:

1) difficulty describing his own or other person's feelings;

2) difficulty distinguishing between bodily feelings and sensations of emotions;

3) constricted symbolization, including scarcity of fantasies;

4) replacing the inner feelings to external events;

5) striving to concrete, unitary, logical thinking, on the background of emotional reactions deficit

The above features can be expressed as equally, or one of them may be expressed by more than others.

The author of the term "alexithymia" is Sifneos [1], below his own description of this phenomenon:

"These people talk about the feelings do not associated with disease, repetitively and endlessly. there are no fantasies in their thoughts, they describe their inner feelings as irritability, emptiness, fatigue, agitation, tension, they show their emotions with great difficulty, they prefer an active lifestyle, they are prone to impulsivity, have scarcity of interpersonal interactions and prefer solitude. Because of these limitations, such patients tend to have difficulty in communicating with other people and appear uninteresting and dull".

In the modern period the study of alexithymia is a multifaceted problem. The main areas of study of this phenomenon are clinical and they psychological concepts and do not reflect the importance of the problem. The general consensus is that the leading risk factor alexithymia regarded as psychosomatic diseases.
There are two types of alexithymia: primary and secondary. Primary alexithymia genetic or has intrauterine (as a result of structural brain damage) character. Secondary alexithymia has a psycho-emotional nature, the main reason is disorder of interaction with mother on the first year of life.

Literary sources reveals a high level of alexithymia in the neuroses and psychosomatic disorders [2,3]. Sung hwa Son et al. [4] had studied the level of alexithymia in depression, somatoform, anxiety and psychotic disorders among Koreans. Although the the authors found high level of alexithymia among most of these patients, these data have no statistical significance. Other authors $[5,6]$ deny the basic role alexithymia in neurotic and psychosomatic disorders, and schizophrenia.

In general, very few amount of research has been devoted to the study of schizophrenia patients with alexithymia, and they are ambiguous

Some researchers [7-9] indicate alexithymia is revealed in patients with schizophrenia.

Li et al. [10] they found that compared with healthy persons, mental patients with schizophrenia level of alexithymia sufficiently high but lower than in patients with depression and mania. Other investigations [11] showed that patients with schizophrenia and post-traumatic stress disorder are more affective level of alexithymia. A number of studies $[12,13]$, found that patients with schizophrenia cannot determine the emotions or it is very difficult to describe emotions [14].

Moskacheva et al. [15] studied emotional and cognitive empathy in 90 healthy individuals. The authors concluded that, despite the high

Correspondence to: Nadir A. Aliyev, Azerbaijan State Advanced Training Institute for Doctors named by A. Aliyev department of psychiatry and drug addiction, Baku, Azerbaijan Republic; E-mail: aliyevnadir@yahoo.com

Key words: alexithymia, schizophrenia and somatic diseases

Received: April 04, 2017; Accepted: April 26, 2017; Published: April 28, 2017 
levels of alexithymia, cognitive empathy is saved, but the emotional empathy is broken in these cases. According to some authors [16-18], one of the major disorders in schizophrenia bound with deficits of perceptual component of emotional intelligence.

Cedro et al. [7] had determined that there is a positive correlation with alexithymia as a paranoid schizophrenia and non-paranoid schizophrenia. In contrast, other authors [9] they noted that the level of alexithymia with the non-paranoid schizophrenia, higher than in paranoid schizophrenia. Some researchers $[7,19]$ suggest that alexithymia and negative symptoms of schizophrenia are associated with each other. Theses authors has determined that the level of alexithymia in schizophrenia is characterized by affective flattening and poor of speech and other symptoms. However, other authors [2] deny this relationship. Theses authors examined the level of alexithymia in 29 patients with schizophrenia. On the background of appropriate treatment for 3, 6 and 12 months, they compared the level of alexithymia with the mental state of patients. On the background of appropriate treatment for 3, 6 and 12 months, they compared the level of alexithymia with the mental state of patients.

The results showed an improvement in the mental state of patients, although the stable level of alexithymia remained unchanged. Nevertheless, the authors believe that the negative symptoms of schizophrenia have nothing to do with the level of alexithymia. That is alexithymia is a structure that is completely different from schizophrenia. But because of the small number of patients studied, this research has limited use, and has not been accepted as a common opinion.

Divilbiss [20] determined that the intensivity of symptoms of schizophrenia, positive, negative symptoms and social functioning are positively associated with alexithymia. But alexithymia has nothing to do with empathy.

The English word empathy is derived from the Ancient Greek word $\varepsilon \mu \pi \dot{\theta} \theta \varepsilon$ เa (empatheia, meaning "physical affection or passion"), that is the capacity to understand or feel what another person is experiencing from within the other being's frame of reference, i.e., the capacity to place oneself in another's position. The author believes that, first of all, in the study of alexitemia, these are negative disorders in patients with schizophrenia.

Henry et al. [6] consider emotional and social changes in behavior to be the most common and devastating consequences of schizophrenia. The authors studied the influence of alexithymia, (which refers to the cognitive aspect of emotions) on schizophrenia. They insist that schizophrenia can not affect alexithymia directly.

The cardinal feature of social isolation in patients with schizophrenia is considered to be social anhedonia [21-23].

Rychkova [24] believes that the scope of emotional disorders in schizophrenia has a large range: direct perception of the impression, Identify the emotions of others in their facial and body expressions, no adequate ability to express their own feelings. The author defined three blocks of emotional disorders - mood in the literal sense, emotional perception and emotional expression.

Van't Wout $\mathrm{M}$ et al. [3] found that the level of alexithymia in patients suffering from schizophrenia is higher in men than in women.

Thus, even in this brief review, the contraversity of the question is obvious, therefore, a comparative study of alexithymia in schizophrenia and with somatic diseases was the purpose of the study.

\section{Materials and methods of research}

Sixty people with schizophrenia and 60 people with somatic diseases were examined.

The criteria for inclusion in the study were: 20-60 years, paranoid form of schizophrenia (F20.0) and somatic diseases - D50, E10, I25, I10, K25, M05 (respectively- anemia due to iron deficiency - 10 people, with type I diabetes mellitus - 10 people with chronic ischemic heart disease - 15, essensiyal (primary) hypertension - 15, gastric ulcer - 10, seropositive rheumatoid arthritis - 10).

Patients suffering from schizophrenia were examined at the Republican Psychiatric Hospital No. 1 of the Ministry of Health, somatic patients had been examined by the Baku Clinical Hospital No. 3 of the Baku City Health Department.

A version of the Toronto Alexithymia Scale (TAS-26) [25], adapted at the Research Institute of Psychoneurology named after VM Bekhterev had been used.

The level of alexithymia is estimated by 5 points: 1) Completely disagree; 2) Most likely don't agree; 3 ) None; 4) Most likely agree; 5) Completely agree

In this version of TAS, the minimum score is 26 , the maximum score is 130 .

62 points and below the score is considered the norm. 63 - 73 points in the "risk group", 74 and above points - is considered as alexithymia.

The mental state of patients with schizophrenia was assessed on the basis of Positive and Negative Syndromes Scale (PNSS).

At the same time, it turned out that the negative symptoms of schizophrenia are relatively more expressive than positive symptoms.

Thus, in order to assess the scale of negative symptoms in patients with schizophrenia, an evaluation was carried out using the negative semi-scale PNSS [26].

The degree of negative symptoms was estimated by a six-point system of 6: 1) None-0;2) slightly - 1;3) Moderately expressed - 2;4) Fairly pronounced - 3 ; 4) significantly expressed $-4 ; 5$ ), severely - $5 ; 6$ ) in extreme degree- 6 .

The statistical processing of the results had been based on the average volume $(\mathrm{M} \pm \mathrm{m})$ and the comparison of two choices - the Mann-Whitney test, and because as the election is more than 50 , instead of the Spearman rank correlation coefficient, the Student test was used (in order to discover a correlation between alexithymia and negative symptoms of schizophrenia). In addition, Yates's correction was used. The accuracy of the results had been determined using the a and $\mathrm{P}$ in the specific Table 1 [27].

\section{Discussion of research results}

The average number of TAS in patients with schizophrenia was 109.73 TAS, and in somatic patients it was 81.66.

The data obtained were processed by the Mann-Whitney method, as a result, their statistical reliability was revealed ( $\alpha \& \mathrm{P}<0,001)$.

In other words, the TAS indices in patients with schizophrenia were higher than those in patients with somatic patients.

During the analysis of TAS answers, changes were identified that were of a general and private nature. 
Table 1. Characteristics of the examined patients

\begin{tabular}{|c|c|c|}
\hline \multirow{2}{*}{ İndicators } & \multicolumn{2}{|c|}{ ICD-10 } \\
\cline { 2 - 3 } & Paranoid form (F20.0) & D50, E10, İ25, I10, K25, M05 \\
\hline Gender: male/female & $30 / 30$ & $32 / 28$ \\
\hline Age (years) $\mathbf{M} \pm \mathbf{m}$ & $45, \pm 1,59$ & $46,0 \pm 1,70$ \\
\hline $\begin{array}{c}\text { Education: } \\
\text { Primary } \\
\begin{array}{c}\text { Secondary } \\
\text { Higher }\end{array}\end{array}$ & 4 & 4 \\
\hline
\end{tabular}

Thus, a common feature for patients with schizophrenia as well as somatic disorders was high scores for TAS1 (it is often difficult for me to understand my own feelings) and TAS 2 answers (I cannot find the right words to express my feelings).

Other answers with high scores are given below:

F20 Schizophrenia: 9, 11, 14, 17, 22.

9. Sometimes I have feelings that are difficult to give a exact name

11. Describing the feelings I have about other people is often difficult

14. When I get angry I find it difficult to identify the feelings causes it

17. I find it difficult to share my feelings with even close friends

22. It's hard for me to describe my feelings towards people

D50 Anemia: 3, 4, 5.

3. I sometimes have such bodily sensations that even doctors do not understand

4. I can easily describe my feelings

5. I would rather analyze the problems than talk about them

\section{E10 Diabetes mellitus type I: 6, 7}

6. When I am upset I find it difficult to identify the feelings causing it- is it yearning, fear or anger?

7. Often I get in a muddle because of the feelings in my body

İ10 Essensiyal hipertoniya: 10, 19, 25

10. It is very important to be aware of your emotions

19. I find it useful to understand my feelings when solving personal problems

25. I am aware of what is happening inside me

İ25 Chronic ischemic heart disease:12, 13, 24.

12. People advise me to talk more about my feelings.

13. I am not aware of what is happening in me

24. It is necessary to seek a deeper explanation of what is happening

K25 Gastric ulcer: 8, 15, 21.

8. I prefer that everything goes on as usual, than to find out why it happened that way

15. I prefer to talk with people about their daily affairs, than about their feelings

21. It is very important to understand your own feelings

M05 seropositive rheumatoid arthritis: 23, 26.

23. People advise me to show more feelings.

26 . I very often do not know why I'm angry
PANSS results in patients with schizophrenia: severity of positive symptoms $=20.0 \pm 1.5$; Severity of negative symptoms $=38.0 \pm 2.0$; Composite Index $=-18$. The severity of the symptomatic symptoms increased mainly with N-1 "flattening of affect"; N-2 "emotional estrangement"; N-3 "Weak (contact)"; N-4 "passive / Apathetic / social detachment"; N-5 "violation of the process of abstraction"; N-7 "Stereotyping of Mind".

As can be seen from the results, in patients with schizophrenia who were included in this study, the severity of the negative symptoms is almost twice the severity of the positive symptoms. It should be noted that the level of alexithymia positively correlates with negative symptoms of schizophrenia, in other words, the higher the level of negative symptoms in schizophrenia, the higher the level of alexithymia.

\section{Results of the study}

1. The study proves that alexymetry is not a feature peculiar to exclusively psychosomatic diseases and neurotic disorders, and that it is equally inherent in schizophrenia, and consequently, all the examined patients had general and particular features of alexithymia.

2. In the examined patients, both with paranoid form of schizophrenia as well as somatic diseases there was a high level of alexithymia. At the same time, compared with somatic patients, patients with paranoid schizophrenia showed a higher level of alexithymia.

3. in the patients with schizophrenia who were included in the study, the severity of the negative symptoms is almost twice the severity of the positive symptoms.

4. It should be noted that the level of alexithymia positively correlates with negative symptoms of schizophrenia, in other words, the higher the level of negative symptoms in schizophrenia, the higher the level of alexithymia.

5. A higher level of alexithymia in paranoid schizophrenia causes a lowering of ability to understand and describe their own and others' feelings, an impedeing of interpersonal relationships, an autotisation and social isolation.

6. The results of this study prove that further investigation of the relationship between schizophrenia and alexithymia is great relevance and promise.

\section{References}

1. Sifneos P (1972) Short-term psychotherapy and emotional crisis. Cambridge, MA: Harvard University Press.

2. Todarello O, Porcelli P, Grilletti F, Bellomo A (2005) Is alexithymia related to negative symptoms of schizophrenia? A preliminary longitudinal study. Psychopathology 38: 310-314. [Crossref]

3. Van 't Wout M, Aleman A, Bermond B, Kahn RS (2007) No words for feelings: alexithymia in schizophrenia patients and first-degree relatives. Compr Psychiatry 48: 27-33. [Crossref]

4. Son S, Jo H, Rim HD, Kim JH, Kim HW, et al. (2012) A Comparative Study on Alexithymia in Depressive, Somatoform, Anxiety, and Psychotic Disorders among Koreans. Psychiatry Investig 9(4): 325-331.

5. Kremleva OV, Geld AL, Kruglov LS (2013) Alexitimic manifestations in anxietydepressive symptoms in mentally ill. Herald of Psychotherapy 46: 60-68 (in Russian).

6. Henry JD, Bailey PE, von Hippel C, Rendell PG, Lane A (2010) Alexithymia in schizophrenia. J Clin Exp Neuropsychol 32: 890-897. [Crossref]

7. Cedro A, Kokoszka A, Popiel A, Narkiewicz-Jodko W (2001) Alexithymia in schizophrenia: an exploratory study. Psychol Rep 89: 95-98. [Crossref] 
8. Serper M, Berenbaum H (2008) The relation between emotional awareness and hallucinations and delusions in acute psychiatric inpatients. Schizophr Res 101: 195200. [Crossref]

9. Stanghellini G, Ricca V (1995) Alexithymia and schizophrenias. Psychopathology 28: 263-272. [Crossref]

10. Li W, Cheng Y, Zhan L, Li L (2009) A comparative study on alexithymia characteristics among three kinds of main hospitalized mental disorders. Chinese Journal of Clinical Psychology 17: 171-172.

11. Spitzer C, Vogel M, Barrow S, Freyburger HJ, Grab HJ (2007) Psychopathology and alexithymia in severe mental illness: the impact of trauma and posttraumatic stress symptoms. Eur Arch Psychiatry Clin Neurosci 257: 191-196.

12. Maggini C, Raballo A (2004) Self-centrality, basic symptoms model and psychopathology in schizophrenia. Psychopathology 37: 69-75. [Crossref]

13. van der Meer L, van't Wout M, Aleman A (2009) Emotion regulation strategies in patients with schizophrenia. Psychiatry Res 170: 108-113. [Crossref]

14. Lysaker PH, Dimaggio G, Buck KD, Carcione A, Nicolo G (2007) Metacognition within narratives of schizophrenia: associations with multiple domains of neurocognition. Schizophr Res 93: 278-287. [Crossref]

15. Moskacheva MA, Kholmogorova AB, Garanyan NG (2014) Alesithymia and the ability to empathy. Consultative psychology and psychotherapy 4: 98-114. (in Russian)

16. Kritskaya VP, Meleshko TK, Yu FP (1991) Pathology of mental activity in schizophrenia: motivation, communication, cognition. Moscow: Moscow State University (in Russian).

17. Kurek NS (1996) Deficiency of mental activity: Passivity of personality and disease. Moscow: IP RAS, (in Russian).
18. Kohler CG, Turner TH, Bilker WB, Brensinger CM, Siegel SJ, et al. (2003) Facial emotion recognition in schizophrenia: intensity effects and error pattern. $A m J$ Psychiatry 160: 1768-1774. [Crossref]

19. Nkam I, Langlois-Thery S, Dollfus S, Petit M (1997) Alexithymia in negative symptom and non- negative symptom schizophrenia. Encephale 23 (5): 358-363.

20. Divilbiss M (2013) The Impact of Alexithymia on Empathic Ability In Schizophrenia. A dissertation submitted to Kent State University in partial fulfillment of the requirements for the degree of Doctor of Philosophy by Marielle Divilbiss.

21. Blanchard JJ, Horan WP, Brown SA (2001) Diagnostic differences in social anhedonia: A longitudinal study of schizophrenia and major depressive disorder. J Abnorm Psychol 110: 363-371.

22. Gard DE, Kring AM, Gard MG, Horan WP, Green MF, et al. (2007) Anhedonia in schizophrenia: Distinctions between anticipatory and consummatory pleasure. Schizophr Res 93: 253-260. [Crossref]

23. Loas G, Noisette C, Legrand A, Boyer P (2000) Is anhedonia a specific dimension in chronic schizophrenia? Schizophr Bull 26: 495-506. [Crossref]

24. Rychkova OV (2012) Emotional components of violations of social perception in schizophrenia. Social and Clinical Psychiatry. 22(4): 22-26. (in Russian)

25. Taylor GJ, Ryan D, Bagby RM (1985) Toward the development of a new self-report alexithymia scale. Psychother Psychosom 44: 191-199. [Crossref]

26. Kay SR, Fiszbein A, Opler LA (1987) The positive and negative syndrome scale (PANSS) for schizophrenia. Schizophr Bull 13: 261-276. [Crossref]

27. Glantz S (1999) Medico-biological statistics. Trans. With eng. Moscow: Practice, 459 (in Russian).

Copyright: (2017 Aliyev NA. This is an open-access article distributed under the terms of the Creative Commons Attribution License, which permits unrestricted use, distribution, and reproduction in any medium, provided the original author and source are credited. 